\title{
Revisiting loxapine: a systematic review
}

\author{
Dina Popovic ${ }^{1}$, Philippe Nuss ${ }^{2}$ and Eduard Vieta ${ }^{1 *}$
}

\begin{abstract}
Loxapine is an antipsychotic used in psychiatry for over 40 years with a well-established profile. Loxapine is a dibenzoxazepine tricyclic antipsychotic agent, available for oral, intramuscular and inhalatory administration. In the light of the recent approval by the regulatory agencies of inhaled loxapine for use in the acute treatment of mild-to-moderate agitation in adults affected with schizophrenia or bipolar disorder, this article aims to critically review the available literature on loxapine, irrespective of its formulation.

This review examines the efficacy and tolerability of the various formulations of loxapine in the treatment of agitation and aggression in patients affected with schizophrenia, bipolar disorder and other psychiatric conditions.

A comprehensive and systematic literature search of PubMed/MEDLINE was conducted, and relevant pharmacodynamic and pharmacokinetic data was included. The findings from the literature were critically reviewed and synthesized.

The available data suggests that the antipsychotic efficacy of loxapine is similar to the efficacy of other typical or atypical antipsychotics, with an adverse effects profile comparable to that of the typical antipsychotics at high doses for chronic treatment. As an acute treatment in agitation associated with schizophrenia or bipolar disorder, inhaled loxapine was developed as an innovative and rapid option which appears to be efficacious and tolerable.
\end{abstract}

Keywords: Loxapine, Antipsychotic, Agitation, Bipolar disorder, Schizophrenia

\section{Introduction}

Loxapine, an antipsychotic that has striking similarities to clozapine, has been recently re-launched as a treatment for agitation in schizophrenia and mania. Acute agitation, characterized by motor restlessness and mental tension, is a serious medical problem that may be present in various psychiatric disorders, including schizophrenia [1] and bipolar disorder [2] and can further escalate into aggressive behaviour [3]. It is important to identify agitation early in its course during its mild stages and achieve results quickly in order to prevent the escalation to aggressive or violent behaviour into more severe stages. In addition to the timely pharmacological treatment, acute interventions that target agitation usually also involve environmental and behavioural approaches [3]. Acute agitation requires prompt intervention to reduce the risk of patient injury and distress and to ensure the safety of other individuals (such as hospital staff, other patients, family members) [4].

\footnotetext{
* Correspondence: evieta@clinic.ub.es

'Bipolar Disorders Program, Hospital Clínic, IDIBAPS, CIBERSAM, University of Barcelona, 170 Villarroel St., Barcelona 08036, Catalonia, Spain

Full list of author information is available at the end of the article
}

The first attempts to treat agitation pharmacologically began with methylene blue, when Paul Erlich found that, when injected into frogs, it selectively stained nerve cells [5]. In 1899, Pietro Bodoni reported on its use to treat psychotic disturbances, in particular to calm psychotic agitation. In addition to morphine and scopolamine (hyoscine) combinations, barbiturates were main agents utilized to cure agitation until Delay and Deniker tested chlorpromazine. This compound was noted to be able to calm the agitation of patients with delirium, mania and psychosis even in monotherapy [5,6]. This observation was followed by numerous others, and the effectiveness of chlorpromazine in the treatment of agitated, overactive and manic states was widely confirmed $[7,8]$.

Emergency sedation for behavioural disturbance in psychiatry in the mid-twentieth century, termed "rapid tranquillization", received increasing attention after the arrival of antipsychotic drugs, which replaced older sedatives and became the agents most strongly associated with the treatment of aggression and challenging behaviour [9-11].

The mental health system was profoundly transformed by the use of antipsychotics. In the 1960s, the use of this 
class of medication was able to deliver effective treatment to outpatient clinics, community mental centres and mental hospitals. One of these compounds, loxapine, has been used for the treatment of schizophrenia since the mid-1970s [12,13] and is nowadays quite widely used in countries like France or Canada. In the light of the recent approval by the regulatory agencies of loxapine inhalation powder (ADASUVE ${ }^{\circ}$ ) in the USA and the EU for use in the acute treatment of agitation in adult patients with schizophrenia or bipolar disorder $[4,14]$, this article aims to critically review the available literature on loxapine irrespective of its formulations.

\section{Methods}

A comprehensive and systematic literature search of all the articles on MEDLINE and PubMed, published up to March 2014 was performed, using the search term "loxapine" cross-referenced with "oral", "bipolar disorder", "schizophrenia", "agitation" and/or "randomized controlled trial". The search was supplemented by manually reviewing reference lists from the identified publications. The search included articles in English, Spanish, German and French. Relevant findings were then identified and synthesized in combination with additional literature regarding the pharmacodynamic and pharmacokinetic data. A general scheme of the output generated by the search is shown in Figure 1.

\section{Results}

\section{Mechanism of action of loxapine}

Loxapine is a dibenzoxazepine tricyclic antipsychotic agent, its chemical structure is similar to clozapine [13] (Figure 2) and is available for oral, intramuscular [13] and, following recent approval, inhalatory route [5].

The efficacy of loxapine is proposed to be mediated through high-affinity antagonism of postsynaptic dopamine D2 receptors and serotonin 5-HT2A receptors [15]. Although classified as a typical antipsychotic, loxapine has atypical characteristics. When antipsychotics are classified as typical or atypical, several considerations need to be kept in mind, including propensity for or lack of motor side effects such as extrapyramidal side effects and tardive dyskinesia and efficacy in treatment of negative symptoms.

The pharmacokinetic and pharmacodynamics properties of loxapine in favour of its atypical characteristics are the following:

- Receptor binding, especially at dopamine-2 (D2) serotonin-2A (5-HT2A) receptors and its high 5HT2/D2 ratio, which is more characteristic of atypical antipsychotics [16-18]. Loxapine has a similar binding affinity as clozapine and olanzapine with a more potent 5-HT2A antagonism.

- Receptor occupancy: antipsychotic blockade of at least $60 \%$ of $\mathrm{D} 2 \mathrm{R}$ in the striatum is necessary for

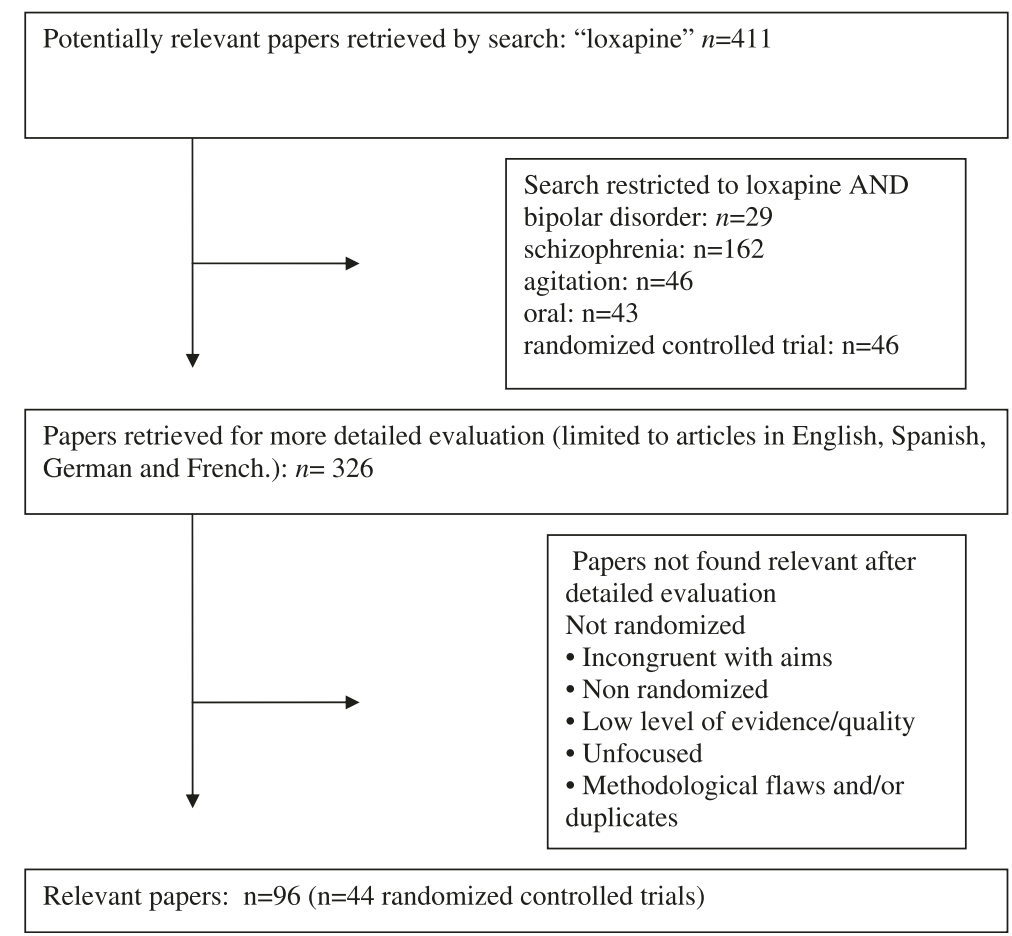

Figure 1 Flow diagram of study design and results. 


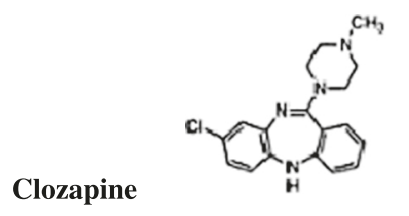

Loxapine $\left(\mathrm{R}=\mathrm{CH}_{3}\right)$

Quetiapine

Amoxapine ( $\mathrm{R}=\mathrm{H})$

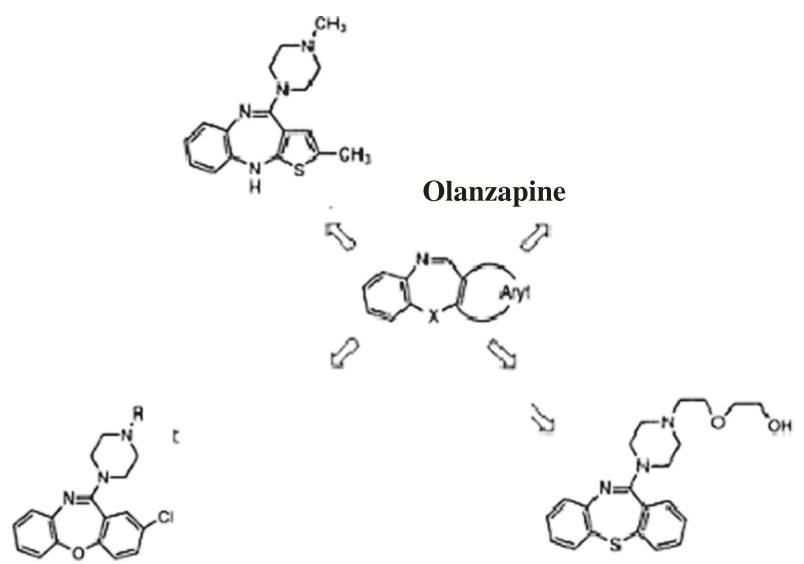

Figure 2 Chemical structure of loxapine, amoxapine, clozapine, quetiapine and olanzapine.

their therapeutic action; however, when $80 \%$ or more of D2 are blocked, EPS are likely to occur. Loxapine at $10-100 \mathrm{mg} /$ day was found to be equipotent at blocking D2 and 5-HT2A receptors [19]. Positron emission tomography imaging revealed D2 receptor occupancy ranging from $43 \%$ to 90\% and 5-HT2A receptor occupancy ranging from $27 \%$ to $>98 \%$; the loxapine dosage required to occupy 50\% of D2 and 5-HT2A receptors was 9.6 and $13.6 \mathrm{mg} /$ day, respectively [19]. Loxapine presents intermediate dissociation from the dopaminergic receptors, identical to olanzapine [20].

- Regarding affinity of other receptors, loxapine binds with higher affinity to D4 receptors than the other dopaminergic receptors, similarly to clozapine $[13,21]$. Additionally, loxapine has a higher affinity for D3 than D2 receptors [22].

- Antagonism of additional receptors: loxapine binds to noradrenergic, histaminergic $\mathrm{H} 1$ and cholinergic M1 receptors [13,23] (Table 1 ). Its interaction with these systems may influence the spectrum of its pharmacological effects that are associated with calming effects and suppression of aggressive behaviour.

The pharmacokinetic characteristics of loxapine are listed in Table 2. Metabolism of loxapine includes demethylation

Table 1 Relative affinities of loxapine for various neurotransmitter receptors

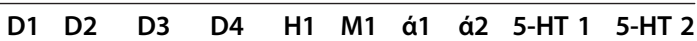

Loxapine $++\quad+++$ +++ +++ ++ + ++ - - $\quad+++$

+++ Very high, ++ high, + moderate, - low. to its primary $\mathrm{N}$-demethylated metabolite amoxapine, a tricyclic antidepressant. The cytochrome P450 (CYP) enzyme CYP1A2 is involved in the hydroxylation of loxapine to 8-OH-loxapine, and CYP3A4 and CYP2D6 are involved in its hydroxylation to 7-OH-loxapine $[10,13,24]$. Loxapine also undergoes $\mathrm{N}$-oxidation by flavonoid monoamine oxidases to form loxapine $\mathrm{N}$-oxide and de-methylation by CYP3A4, CYP2C19 and CYP2C8 to form amoxapine. 8-OH-loxapine has no pharmacological activity at the D2 receptor, although 7-OHloxapine (a minor metabolite) binds to D2 receptors with high affinity $[10,13]$.

\section{Efficacy and tolerability of loxapine}

The efficacy and tolerability of loxapine were well established through its large period of use not only in chronic and continuous treatment for schizophrenia or other psychiatric conditions [22] but also in acute psychotic stages.

\section{The use of loxapine in schizophrenia}

A 2007 Cochrane review included 41 studies, comparing loxapine to haloperidol, thiothixene, risperidone, clozapine and quetiapine [22]. As emerging from the review, compared with placebo, loxapine has an antipsychotic effect, based on the results of two randomized controlled trials (RCT), with a number needed to treat (NNT) of 3 [CI 3-5]. It is as effective as typical drugs in the short term (4-12 weeks) according to 13 RCTs. Very limited heterogeneous data suggest that, given intramuscularly (IM), loxapine may be at least as sedating as IM haloperidol and thiothixene [22]. 
Table 2 Pharmacokinetic parameters of loxapine

\begin{tabular}{ll}
\hline pKa & 6.6 \\
\hline Half-life & $4 \mathrm{~h}$ (range 1-14) \\
Intramuscular & $12 \mathrm{~h}$ (range 8-23) \\
Inhalatory route & $4 \mathrm{~h}$ (range 6-8) \\
Time to peak concentration & \\
Route oral & $1 \mathrm{~h}$ \\
Intramuscular & $5 \mathrm{~h}$ \\
Inhalatory route & 2 min (1-3) \\
Metabolites & 7 - and 8-Hydroxyloxapine \\
& Desmethyl-loxapine (amoxapine) \\
& 7 - and 8-Hydroxyamoxapine \\
& loxapine N-oxide \\
& Excretion of glucuronide conjugates \\
in urine & Unchanged in faeces \\
\hline
\end{tabular}

According to data deriving from six RCTs, loxapine was also found as effective as atypicals (risperidone, quetiapine) and typicals such as perphenazine [25] and trifluoperazine [26] in small, head to-head trials [27]. The trial characteristics of the included trials are described in Additional file 1.

Regarding the tolerability of loxapine, common side effects of oral loxapine include parkinsonian-like symptoms such as tremor, hypomimia, rigidity, akathisia, drowsiness, dry mouth, constipation and weight changes [27].

According to a population-based cohort study of elderly people, the risk of death associated with conventional antipsychotic medications is comparable to and possibly greater than the risk of death associated with atypical antipsychotic medications [28]. In comparison with risperidone, haloperidol was associated with the greatest increase in mortality (mortality ratio 2.14, 95\% CI 1.86-2.45) and loxapine, the lowest (mortality ratio 1.29, 95\% CI 1.19-1.40) [29].

To date, no definitive association has been found between the use of antipsychotics during pregnancy and an increased risk of birth defects or other adverse outcomes. There are no studies concerning loxapine use in pregnancy in the literature, and the manufacturer reports outcomes from only three pregnancies with loxapine exposure: one child born with achondroplasia, one child born with multiple unspecified malformations and one child with tremors at 15 weeks of age [30]. However, the retrospective nature of these reports does not permit to reach conclusions regarding the safety of this drug in pregnancy. Overall, there is a paucity of information, with a lack of large, well-designed, prospective comparative studies on the safety of antipsychotics in pregnancy [30].

\section{The use of loxapine in bipolar mania}

Acute mania frequently constitutes a medical emergency, requiring prompt intervention to avoid destructive and possibly life-endangering behaviour [31]. Although it is evident that patients with acute bipolar mania require rapid and effective treatments that safely control this dangerous process [32], there is a paucity of empirical data regarding speed of action of antimanic treatments, an extremely important issue in clinical practice [33]. As shown in a recent meta-analysis, haloperidol has a faster onset of antimanic action than second-generation antipsychotics [33] although it also carries greater risk of switch into depression [34].

Chlorpromazine and haloperidol are the most studied typical antipsychotics in the treatment of bipolar mania [35]. One small placebo-controlled study supports the efficacy of chlorpromazine [36] while several studies support the efficacy of haloperidol in this indication. The first publications date back to 1975 [24], while more recent studies support the efficacy of up to $30 \mathrm{mg} /$ day of haloperidol for the treatment of acute mania, with a response rate vs. placebo at 3 weeks of $47-56.1 \%$ vs. $20-$ $35 \%$, respectively [37-41]. To date, there have been no trials assessing the efficacy of the oral or intramuscular formulation of loxapine in acute treatment of manic episode. One RCT found inhaled loxapine effective in the reduction of agitation as early as $10 \mathrm{~min}$ after first administration in bipolar patients in manic or mixed episode [42]. Typical antipsychotics such as haloperidol, zuclopenthixol or loxapine are still widely prescribed in the treatment of mania, due to the need to acquire adequate and rapid sedation or even the so-called chemical containment [43]. However, the treatment with typical antipsychotics carries a potential risk and associated side effects such as extrapyramidal side effects, depressogenic effect and malignant syndrome [43]. It is noteworthy that some authors have established that the patients affected with mood disorders are more prone to develop extrapyramidal side effects than the schizophrenic patients $[44,45]$, which may contribute to limit the prescription of typical antipsychotics in this population beyond punctual administration.

\section{Loxapine in the treatment of agitation across psychiatric disorders}

Timely treatment of agitation is essential, also considering that it can further escalate into aggressive behaviour. Aggressive behaviour is variable in intensity and targets with a wide range of expression either verbal, against objects, self or other persons (frequently called violence) [3].

Reports evaluating loxapine's effects date back to the 1970s. Five small-scale, randomized, double-blind trials studies assessed the relationship between loxapine treatment and aggression [46-50]. Whatsoever, the small sample 
sizes (from 30 to 54 patients) in all of these studies limit the generalisability of the findings.

Although data supports the use of haloperidol as an efficacious treatment of aggression in autistic disorder [51-54], the empirical data is less clear regarding the utility of the other typical antipsychotics in this patient population. Only anecdotic reports suggest anti-aggressive effects of loxapine [55] and amoxapine in autistic children [56], but there is a clear need for additional research in autistic and other psychiatric populations.

Recently, inhaled loxapine (ADASUVE) has been approved by the Food and Drug Administration and European Medical Agency for the acute treatment of agitation associated with schizophrenia or bipolar disorder in adults. The approval was based on one phase II and two phase III efficacy trials in the treatment of acute agitation in the above-mentioned disorders $[42,57,58]$. In two phase III studies (one in subjects with schizophrenia, the other in subjects with bipolar disorder) inhaled loxapine doses of 5 and $10 \mathrm{mg}$ were both superior to placebo $10 \mathrm{~min}$ after administration. Pooled data from these three efficacy studies suggest a NNT for response of 4 (95\% CI 3-5) and 3 (95\% CI 3-4) for inhaled loxapine (5 or $10 \mathrm{mg}$ vs. placebo) for agitation associated with schizophrenia or bipolar disorder, respectively. These values are in the range with effect size observed for intramuscular administration of other antipsychotics [59].

According to data pooled from the three existing efficacy studies of inhaled loxapine, no clinically relevant extrapyramidal side effects or akathisia have emerged following administration of loxapine $10 \mathrm{mg}$ or $5 \mathrm{mg}$, and the most commonly encountered adverse event was short-term dysgeusia, with a number needed to harm vs. placebo of 10 (95\% CI 7-22) or 12 (95\% CI 8-26), respectively [59]. Given that the route of administration is inhalation, active airways disease (asthma and chronic obstructive pulmonary disease) are contraindicated due to the risk of bronchospasm [27]. There is no apparent QT prolongation associated with the therapeutic dose of inhaled loxapine [60].

\section{Discussion}

The present review of the available literature derives from the large experience of 40 years of loxapine use in chronic treatment of psychiatric disorders and their agitated stages.

The systematic Cochrane review assessing all randomized controlled trials that compared loxapine (in dosages up to $300 \mathrm{mg} /$ day) to other chronic treatments in schizophrenia concluded that loxapine was not distinct from typical or atypical drugs in terms of its effects on global or mental state and exhibited a similar adverse effect profile to typical antipsychotics but may cause more extrapyramidal adverse effects when compared with atypical antipsychotics [22].
Furthermore, loxapine is more effective than other 'typical' antipsychotics in reducing the negative symptoms of schizophrenia [57]. Extrapyramidal side effects are not usually observed at clinically effective antipsychotic doses [61]. Loxapine, although classified as a conventional antipsychotic, at low doses $(<50 \mathrm{mg} /$ day $)$ may be considered as an atypical one $[13,18]$.

Considering the above-mentioned data, and with the aim of improving the treatment of agitated patients with schizophrenia and bipolar disorder [62], inhaled loxapine was developed and approved as an effective and tolerable option. This innovative approach could be a good option in the management of agitation, intercepting the escalation to its severe stages.

Existing evidence supports the efficacy of clozapine in reducing suicidal behaviour in patients with schizophrenia [63-68]. In view of the similarities between clozapine and loxapine, future studies should investigate potential anti-suicidal properties of loxapine.

\section{Conclusions}

Data suggests that loxapine is an antipsychotic drug with an efficacy similar to other typical or atypical agents in terms of antipsychotic efficacy and adverse effects profile similar to that of the typical antipsychotics at high doses for the chronic treatment. As an acute treatment of agitation associated with schizophrenia or bipolar disorder, inhaled loxapine, as delivered through a fast-heating device (Staccato), was developed as an innovative and particularly rapid pharmacological option which appears to be efficacious and tolerable in most clinical settings where psychiatric agitation is problematic.

\section{Additional file}

Additional file 1: Characteristics of the included trials [69-102].

\section{Competing interests}

Ferrer provided unrestricted support for the development of this paper. Dr. Popovic has served as a speaker and/or medical writer for Bristol-Myers Squibb, Merck Sharp \& Dohme, Janssen-Cilag and Ferrer.

Dr Nuss has served as a consultant, adviser or speaker for AstraZeneca, Bristol-Myers Squibb, Ferrer, Janssen-Cilag, Lundbeck, Otsuka, Sanofi-Aventis and Servier.

Prof. Vieta has received research support from or served as a consultant, adviser or speaker for Alexza, Almirall, AstraZeneca, Bristol-Myers Squibb, Elan, Eli Lilly, Ferrer, Forest Research Institute, 7th Framework Program of the European Union, Geodon Richter, GlaxoSmithKline, Janssen-Cilag, Jazz, Lundbeck, Merck, Novartis, Organon, Otsuka, Pfizer, Roche, Sanofi-Aventis, Servier, Solvay, Schering-Plough, Shire, Spanish Ministry of Science and Innovation, Stanley Medical Research Institute, Takeda, Teva, United Biosource Corporation and Wyeth.

\section{Authors' contributions}

DP and EV performed the review of the available literature. DP drafted the manuscript. EV and PN participated in design of the study and critically revised the manuscript. All authors read and approved the final version of the manuscript. 


\section{Acknowledgements}

Dr. Popovic's work is supported by a Sara Borrell post-doctoral grant (CD13/ 00149), provided by Carlos III Institute, Ministry of Science and Innovation of Spain.

\section{Author details CNRS LBM, Paris, France. \\ Received: 1 December 2014 Revised: 16 February 2015 \\ Accepted: 10 March 2015 \\ Published online: 01 April 2015}

'Bipolar Disorders Program, Hospital Clínic, IDIBAPS, CIBERSAM, University of Barcelona, 170 Villarroel St., Barcelona 08036, Catalonia, Spain. ${ }^{2}$ Psychiatry and Medical Psychology Department, Hôpital Saint-Antoine, AP-HP, Paris, France and Sorbonne Universités-UPMC Univ Paris 06, UMR 7203, INSERM ERL 1157,

\section{References}

1. Osser DN, Sigadel R. Short-term inpatient pharmacotherapy of schizophrenia. Harv Rev Psychiatry. 2001;9:89-104.

2. Alderfer BS, Allen MH. Treatment of agitation in bipolar disorder across the life cycle. J Clin Psychiatry. 2003;64 suppl 4:3-9.

3. Citrome L, Volavka J. The psychopharmacology of violence: making sensible decisions. CNS Spectr. 2014;26:1-8.

4. Keating GM. Loxapine inhalation powder: a review of its use in the acute treatment of agitation in patients with bipolar disorder or schizophrenia. CNS Drugs. 2013;27(6):479-89.

5. Healy D. The creation of psychopharmacology. Massachusetts London, England: Harvard University Press Cambridge; 2004.

6. Delay J, Deniker P, Harl JM. Traitement des ètats d'excitation et d'agitation par une méthode médicamenteuse dérivè de l'hibernothèrapie. Ann Med Psychol. 1952;110:267-73.

7. Angst J, Bente D, Berner P, Heimann H, Helmchen H, Hippius H. Das klinische Wirkungsbild von Clozapin. Pharmakopsychiatrie. 1971;4:201-21.

8. Angst J, Jaenicke U, Padrutt A, Scharfetter C. Ergebnis eines Doppelblindversuches von HF 1854 im vergleich zu Levomepromazin. Pharmakopsychiatr Neuropsychopharmakol. 1971;4:192-200.

9. Allison L, Moncrieff J. 'Rapid tranquillisation': an historical perspective on its emergence in the context of the development of antipsychotic medications. Hist Psychiatry. 2014;25(1):57-69.

10. Scull A. Was insanity increasing? A response to Edward Hare. Brit J Psych. 1984;144:432-6.

11. Divry P, Bobon J, Collard J. Le R1625, nouvelle thérapeutique symptomatique de l'agitation psychomotrice. Acta Neurol Psychiatr Belg. 1958;58:878-88.

12. Schiele BC. Loxapine succinate: a controlled double-blind study in chronic schizophrenia. Dis Nerv Syst. 1975;36(7):361-4.

13. Mazzola CD, Miron S, Jenkins AJ. Loxapine intoxication: case report and literature review. J Anal Toxicol. 2000;24(7):638-41.

14. European Medicines Agency. Adasuve (loxapine) inhalation powder: EU summary of product characteristics; 2013. http://ec.europa.eu/health/ documents/community-register/html/h823.htm (Accessed 22-Jan-2013)

15. Kapur S, Zipursky R, Remington G, Jones C, McKay G, Houle S. PET evidence that loxapine is an equipotent blocker of $5-\mathrm{HT} 2$ and D2 receptors: implications for the therapeutics of schizophrenia. Am J Psychiatry. 1997; 154(11):1525-9.

16. Buckley PF. The role of typical and atypical antipsychotic medications in the management of agitation and aggression. J Clin Psychiatry. 1999;60:52-60.

17. Stahl SM. Selecting an atypical antipsychotic by combining clinical experience with guidelines from clinical trials. J Clin Psychiatry. 1999;60:31-41.

18. Glazer WM. Does loxapine have "atypical" properties? Clinical evidence. J Clin Psychiatry. 1999;60:42-6.

19. Lambert PA. Classification des neuroleptiques. In: Achaintre A, Balvet $P$, Beaujard M, Becache A, Berthier C, Broussolle P, editors. Actualities de therapeutique psychiatrique. Paris: Masson et Cie; 1963.

20. Seeman P. Targeting the dopamine D2 receptor in schizophrenia. Expert Opin Ther Targets. 2006;10(4):515-31.

21. Roth BL, Tandra S, Burgess LH, Sibley DR, Meltzer HY. D4 dopamine receptor binding affinity does not distinguish between typical and atypical antipsychotic drugs. Psychopharmacology (Berl). 1995;120(3):365-8.
22. Chakrabarti A, Bagnall AM, Chue P, Fenton M, Palaniswamy V, Wong W, et al. Loxapine for schizophrenia. Cochrane Database Syst Rev. 2007;4:CD001943.

23. Ereshefsky L. Pharmacologic and pharmacokinetic considerations in choosing an antipsychotic. J Clin Psychiatry. 1999;60:20-30.

24. Shopsin B, Gershon S, Thompson H, Collins P. Psychoactive drugs in mania: a controlled comparison of lithium carbonate, chlorpromazine, and haloperidol. Arch Gen Psychiatry. 1975;32:34-42.

25. Fruensgaard K, Wollenberg J, Hansen KM, Fensbo C, Sihm F. Loxapine versus perphenazine in psychotic patients: a doubleblind, randomized, multicenter trial. Curr Med Res Opin. 1978;5(8):601-7.

26. Simpson GM, Cuculic Z. A double-blind comparison of loxapine succinate and trifluoperazine in newly admitted schizophrenic patients. J Clin Pharmacol. 1976;16:60-5.

27. Nordstrom K, Allen MH. Alternative delivery systems for agents to treat acute agitation: progress to date. Drugs. 2013;73(16):1783-92.

28. Schneeweiss S, Setoguchi S, Brookhart A, Dormuth C, Wang PS. Risk of death associated with the use of conventional versus atypical antipsychotic drugs among elderly patients. CMAJ. 2007;176(5):627-32.

29. Comai S, Tau M, Pavlovic Z, Gobbi G. The psychopharmacology of aggressive behavior: a translational approach: part 2: clinical studies using atypical antipsychotics, anticonvulsants, and lithium. J Clin Psychopharmacol. 2012;32(2):237-60.

30. Einarson A, Boskovic R. Use and safety of antipsychotic drugs during pregnancy. J Psychiatr Pract. 2009;15(3):183-92.

31. Belmaker RH. Bipolar disorder. N Engl J Med. 2004;351(5):476-86.

32. Keck PE, McElroy SL, Bennett JA. Pharmacologic loading in the treatment of acute mania. Bipolar Disord. 2000;2:42-6.

33. Goikolea JM, Colom F, Capapey J, Torres I, Valenti M, Grande I. Faster onset of antimanic action with haloperidol compared to second-generation antipsychotics: a meta-analysis of randomized clinical trials in acute mania. Eur Neuropsychopharmacol. 2013;23(4):305-16.

34. Goikolea JM, Colom F, Torres I, Capapey J, Valentí M, Undurraga J, et al. Lower rate of depressive switch following antimanic treatment with second-generation antipsychotics versus haloperidol. J Affect Disord. 2013;144(3):191-8.

35. Tohen M, Vieta E. Antipsychotic agents in the treatment of bipolar mania. Bipolar Disord. 2009;11 Suppl 2:45-54.

36. Klein DF. Importance of psychiatric diagnosis in prediction of clinical drug effects. Arch Gen Psychiatry. 1967:16:118-26.

37. Mclntyre RS, Brecher M, Paulsson B, Huizar K, Mullen J. Quetiapine or haloperidol as monotherapy for bipolar mania-a 12-week, double-blind, randomised, parallel-group, placebo-controlled trial. Eur Neuropsychopharmacol. 2005;15:573-85.

38. Smulevich AB, Khanna S, Eerdekens M, Karcher K, Kramer M, Grossman F. Acute and continuation risperidone monotherapy in bipolar mania: a 3-week placebo-controlled trial followed by a 9-week double-blind trial of risperidone and haloperidol. Eur Neuropsychopharmacol. 2005;15:75-84.

39. Vieta E, Ramey T, Keller D, English PA, Loebel AD, Miceli J. Ziprasidone in the treatment of acute mania: a 12-week, placebo-controlled, haloperidolreferenced study. J Psychopharmacol. 2010;24:547-58.

40. Young AH, Oren DA, Lowy A, McQuade RD, Marcus RN, Carson WH, et al. Aripiprazole monotherapy in acute mania: 12-week randomised placeboand haloperidol-controlled study. Br J Psychiatry. 2009;194:40-8.

41. Fountoulakis KN, Kasper S, Andreassen O, Blier P, Okasha A, Severus E, et al. Efficacy of pharmacotherapy in bipolar disorder: a report by the WPA section on pharmacopsychiatry. Eur Arch Psychiatry Clin Neurosci. 2012;262 Suppl 1:1-48

42. Kwentus J, Riesenberg RA, Marandi M, Manning RA, Allen MH, Fishman RS, et al. Rapid acute treatment of agitation in patients with bipolar I disorder: a multicenter, randomized, placebo-controlled clinical trial with inhaled loxapine. Bipolar Disord. 2012;14:31-40.

43. Bourin M, Lambert O, Guitton B. Treatment of acute mania-from clinical trials to recommendations for clinical practice. Hum Psychopharmacol. 2005;20(1):15-26.

44. Nasrallah HA, Churchill CM, Hamdan-Allan GA. Higher frequency of neuroleptic-induced dystonia in mania than in schizophrenia. Am J Psychiatry. 1993;145:1455-6.

45. Kane JM. Tardive dyskinesia in affective disorders. J Clin Psychiatry. 1999;60 Suppl 5:43-7.

46. Fruensgaard K, Korsgaard S, Jorgensen H, Jensen K. Loxapine versus haloperidol parenterally in acute psychosis with agitation: a double-blind study. Acta Psychiatr Scand. 1977;56:256-64. 
47. Moyano CZ. A double-blind comparison of loxitane loxapine succinate and trifluoperazine hydrochloride in chronic schizophrenic patients. Dis Nerv Syst. 1975;36:301-4.

48. Paprocki J, Versiani M. A double-blind comparison between loxapine and haloperidol by parenteral route in acute schizophrenia. Curr Ther Res Clin Exp. 1977;21:80-100.

49. Selman FB, McClure RF, Helwig H. Loxapine succinate: a double-blind comparison with haloperidol and placebo in acute schizophrenics. Curr Ther Res Clin Exp. 1976;19:645-52.

50. Tuason VB. A comparison of parenteral loxapine and haloperidol in hostile and aggressive acutely schizophrenic patients. J Clin Psychiatry. 1986;47:126-9.

51. Anderson LT, Campbell M, Grega DM, Perry R, Small AM, Green WH. Haloperidol in the treatment of infantile autism: effects on learning and behavioral symptoms. Am J Psychiatry. 1984;141(10):1195-202.

52. Anderson LT, Campbell M, Adams P, Small AM, Perry R, Shell J. The effects of haloperidol on discrimination learning and behavioral symptoms in autistic children. J Autism Dev Disord. 1989;19(2):227-39.

53. Campbell M, Anderson LT, Small AM, Perry R, Green WH, Caplan R. The effects of haloperidol on learning and behavior in autistic children. J Autism Dev Disord. 1982;12(2):167-75.

54. Campbell M, Anderson LT, Meier M, Cohen IL, Small AM, Samit C, et al. A comparison of haloperidol and behavior therapy and their interaction in autistic children. J Am Acad Child Psychiatry. 1978;17(4):640-55.

55. Reinblatt SP, Abanilla PK, Jummani R, Coffey B. Loxapine treatment in an autistic child with aggressive behavior: therapeutic challenges. J Child Adolesc Psychopharmacol. 2006;16(5):639-43.

56. Craven-Thuss B, Nicolson R. Amoxapine treatment of interfering behaviors in autistic disorder. J Am Acad Child Adolesc Psychiatry. 2003;42(5):515-6.

57. Lesem MD, Tran-Johnson TK, Riesenberg RA, Feifel D, Allen MH, Fishman R, et al. Rapid acute treatment of agitation in individuals with schizophrenia: multicentre, randomised, placebo-controlled study of inhaled loxapine. $\mathrm{Br} J$ Psychiatry. 2011;198(1):51-8.

58. Allen MH, Feifel DA, Lesem MD, Zimbroff DL, Ross R, Spyker DA, et al. Efficacy and safety of loxapine for inhalation in the treatment of acute agitation in patients with schizophrenia: a randomized, double-blind, placebo-controlled trial. J Clin Psychiatry. 2011;72(10):1313-21.

59. Citrome L. Aerosolised antipsychotic assuages agitation: inhaled loxapine for agitation associated with schizophrenia or bipolar disorder. Int J Clin Pract. 2011;65(3):330-40.

60. Spyker DA, Voloshko P, Heyman ER, Cassella JV. Loxapine delivered as a thermally generated aerosol does not prolong QTc in a thorough QT/QTC study in healthy subjects. J Clin Pharmacol. 2014;54(6):665-74.

61. Vanelle JM, Olie JP, Levy-Soussan P. New antipsychotics in schizophrenia: the French experience. Acta Psychiatr Scand, Supplementum. 1994;380:59-63.

62. Vieta E. The bipolar maze: a roadmap through translational psychopathology. Acta Psychiatr Scand. 2014;129(5):323-7.

63. Popovic D, Benabarre A, Crespo JM, Goikolea JM, González-Pinto A, GutiérrezRojas $L$, et al. Risk factors for suicide in schizophrenia: systematic review and clinical recommendations. Acta Psych Scand. 2014;130(6):418-26.

64. Meltzer HY, Okayli G. Reduction of suicidality during clozapine treatment of neuroleptic-resistant schizophrenia: impact on risk-benefit assessment. Am J Psychiatry. 1995;152:183-90.

65. Munro J, O'sullivan D, Andrews C, Arana A, Mortimer A, Kerwin R. Active monitoring of 12,760 clozapine recipients in the UK and Ireland: beyond pharmacovigilance. Br J Psychiatry. 1999;175:576-80.

66. Reid WH, Mason M, Hogan T. Suicide prevention effects associated with clozapine therapy in schizophrenia and schizoaffective disorder. Psychiatr Serv. 1998:40:1029-33.

67. Walker AM, Lanza LL, Arellano F, Rothman KJ. Mortality in current and former users of clozapine. Epidemiology. 1997;8:671-7.

68. Meltzer HY, Alphs L, Green A, Altamura AC, Anand R, Bertoldi A, et al. Clozapine treatment for suicidality in schizophrenia: international suicide prevention trial (InterSePT). Arch Gen Psychiatry. 2003;60:82-91.

69. Bagadia VN, Shah LP, Abhyankar RR. A double-blind controlled trial of loxapine and trifluoperazine in adolescent schizophrenia. Curr Ther Res Clin Exp. 1980;27(6):886-96

70. Bishop MP, Gallant DM. Loxapine: a controlled evaluation in chronic schizophrenic patients. Curr Ther Res Clin Exp. 1970;12(9):594-7.

71. Charalampous KD, Freemesser GF, Malev J, Ford K. Loxapine succinate: a controlled double blind study in schizophrenia. Curr Ther Res. 1974;6(8):829-37.
72. Clark ML, Huber WK, Sullivan J, Wood F, Costiloe JP. Evaluation of loxapine succinate in chronic schizophrenia. Dis Nerv Syst. 1972;33:783-91.

73. Clark ML, Paredes A, Costiloe JP, Wood F, Barrett A. Loxapine in newly admitted chronic schizophrenic patients. J Clin Pharmacol. 1975;15(4):286-94.

74. Clark ML, Paredes A, Costiloe JP, Fulkerson FG, Wood F. Evaluation of two dose levels of loxapine succinate in chronic schizophrenia. Dis Nerv Syst. 1977;38(1):7-10.

75. Du B-G, Fang R-L. Control studies on curative effects of loxapine succinate and risperidone in schizophrenics. J Clin Psychosomatic Dis. 2003;9(1):16-9.

76. Dube KC, Kumar N. Loxapine succinate: a comparative study with chlorpromazine. Curr Ther Res Clin Exp. 1976;19(6):653-60.

77. Dubin WR, Weiss KJ. Rapid tranquilization: a comparison of thiothixene with loxapine. J Clin Psychiatry. 1986;47(6):294-7.

78. Gallant B. Oxilapine versus trifluoperazine. Psychopharmacol Bull. 1971;7(1):40-3

79. Huang S, Qin Y, Wang L. Study on the efficacy of loxapine in treatment of schizophrenia in comparison with chlorpromazine. Chinese New Drugs J. 1997;6(3):161-4

80. Kiloh LG, Williams SE, Grant DA, Whetton PS. A double-blind comparative trial of loxapine and trifluoperazine in acute and chronic schizophrenic patients. J Int Med Res. 1976;4(6):441-8.

81. Kramer MR, Thomas SPJ, Zorick FJ, Blackwell B. Relative efficacy and safety of loxapine succinate (Loxitane) and thioridazine hydrochloride (Mellaril) in the treatment of acute schizophrenia. Curr Ther Res. 1978;23(5):619-31.

82. Li Y, Shang J, Li C. Control study of loxapine succinate and clozapine on curative effects in treatment of schizophrenics. Heath Psychol J. 2004;12(3):202

83. Li L-X, Li C-Y. A comparative study of loxapine succinate and risperidone in the treatment of schizophrenia. Shandong Arch Psychiatry. 2005;18(4):246-7.

84. Z-y L, Rui-fang HE. Comparative study between loxapine and risperedone in treatment of schizophrenia. J Clin Psychol Med. 2005;15(1):11-2.

85. Liu. Control study of loxapine and chlorpromazine in the treatment of schizophrenia. Med J ChinesePeople's Health. 2005;17(9):503-4.

86. Lu X-Q, Zhu G-L. Control studies of loxapine succinate and clozapine in treatment of schizophrenia. J Clin Psychosom Dis. 2003;9(3):157-8.

87. Malik SC, Kumar K. Loxapine in adolescent schizophrenia-a comparative study with trifluoperazine. Curr Ther Res Clin Exp. 1980;28(3):432-46.

88. Moore DF. Treatment of acute schizophrenia with loxapine succinate (Loxitane) in a controlled study with chlorpromazine. Curr Ther Res. 1975;18(1):172-80.

89. Pool D, Bloom W, Mielke DH, Roniger Jr JJ, Gallant DM. A controlled evaluation of loxitane in seventy-five adolescent schizophrenic patients. Curr Ther Res. 1976;19(1):99-104.

90. Rifkin A, Rieder E, Sarantakos S, Saraf K, Kane J. Isloxapine more effective than chlorpromazine in paranoid schizophrenia? Am J Psychiatr. 1984;141(11):1411-3.

91. Seth S, Mahal AS, Kumar KA. A double-blind comparative trial of loxapine and trifluperazine in chronic schizophrenic patients. Curr Ther Res. 1979;25(2):320-9.

92. Shopsin B, Pearson E, Gershon S, Collins P. A controlled double-blind comparison between loxapine succinate and chlorpromazine in acute newly hospitalized schizophrenic patients. Curr Ther Res Clin Exp. 1972;14(11):739-48.

93. Steinbook R, Goldstein BJ, Brauzer B, Moreno SS, Jacobson AF. Loxapine: a double blind comparison with chlorpromazine in acute schizophrenic patients. Curr Ther Res Clin Exp. 1973;15(1):1-7.

94. Tu Z-M, Gao S-R, Ye S-N. Controlled study of loxapineand chlorpromazine in the treatment of schizophrenia. Med J Chinese People's Health. 2004;16(7):415-7

95. Tuason VB, Escobar Jl, Garvey M, Schiele B. Loxapine versus chlorpromazine in paranoid schizophrenia: a double-blind study. J Clin Psychiatry. 1984;45(4):158-63.

96. Van Der Velde CD, Kiltie H. Effectiveness of loxapine succinate in acute schizophrenia: a comparative study with thiothixene. Curr Ther Res. 1975;17(1):1-12.

97. Vyas BK, Kalla V. A six-month double-blind comparison of loxapine succinate and chlorpromazine in chronic schizophrenic patients. Curr Ther Res Clin Exp. 1980;28(1):16-30.

98. Wang L, Wang Z, Wang Y. Using loxapine succinate and chlorpromazine for treating schizophrenia. Tianjing Med J. 1996;24(11):672-5.

99. Wang. Control study of loxapine and quetiapine treating first onset schizophrenia. Chinese J Behav Med Sci. 2005;14(8):752. 
100. Wang $\mathrm{H}-\mathrm{Y}$, Wang G-P, Pei G-X. A comparative study of loxapine and risperidone in the treatment of schizophrenic patients. Shandong Arch Psychiatry. 2005;18(1):28-9.

101. Xue S-J, Huang J-M, Yang M-Z. A comparison study on loxapine and chlorpromazine in the treatment of schizophrenia. Med J Chinese People's Health. 2004;16(10):593-4.

102. Zhang. Control study of loxapine treatment in schizophrenia. Sichuan Mental Health. 2005;18(4):222-4.

Submit your next manuscript to BioMed Central and take full advantage of:

- Convenient online submission

- Thorough peer review

- No space constraints or color figure charges

- Immediate publication on acceptance

- Inclusion in PubMed, CAS, Scopus and Google Scholar

- Research which is freely available for redistribution 